\title{
Relationship between the Meiyu over the Yangtze-Huaihe River Basins and the Frequencies of Tropical Cyclone Genesis in the Western North Pacific
}

\author{
Yanju LIU, Yihui DING and Yafang SONG \\ National Climate Center, China Meteorological Administration, Beijing, China
}

(Manuscript received 18 May 2010, in final form 6 October 2010)

\begin{abstract}
The relationship between the Meiyu precipitation over the Yangtze-Huaihe River Basins (YHRB) and the frequencies of tropical cyclone (TC) genesis in the western North Pacific (WNP) for the period 1951-2006 has been investigated in the present paper. The results have shown that there exists a significant negative correlation between them, which is due to the fundamental changes in monsoonal airflows and associated moisture transports over East Asia and the WNP. In the years with fewer TCs genesis, the location of the main body of the subtropical high over the WNP is farther west and south, and its intensity is abnormally stronger. The monsoon trough also shifted farther west, with a weaker intensity. Under this condition, the monsoon flow and the corresponding moisture transport can not extend eastward down to the WNP, but turns to the East Asian region along the western flank of the subtropical anticyclone over the South China Sea (SCS). Meanwhile, the westerlies at mid-latitudes are located farther south with a stronger intensity. This kind of circulation conditions is favorable for the convergence of the dry and cold air from the mid- and high latitudes and the warm and moist air from the low latitudes over the YHRB, and leads to more precipitation there.

In the years with more TCs, the subtropical high over the WNP is located farther north and east, with its intensity being weaker. The monsoon trough zonally extends eastward down to the open sea of the WNP. Most of the monsoon flow and the associated moisture transport from the tropical Indian Ocean can all the way reach the WNP, with a smaller proportion turning northward to the East Asian Meiyu region over the SCS, which is favorable for the genesis and development of TC in the WNP. At the same time, the location of the mid-latitude westerlies is farther north and its intensity is weaker, which is unfavorable for the occurrence of the precipitation over the YHRB. This kind of negative correlation relationship will be conducive to the seasonal forecast of the TC and the Meiyu during the rainy season in China.
\end{abstract}

Key words: Meiyu over the Yangtze-Huaihe River Basin, western North Pacific, tropical cyclone, negative correlation.

\section{Introduction}

Tropical cyclone (TC) (including tropical storm and typhoon) and Meiyu are of the most frequently occurring meteorological phenomena in East Asia, which have significant influences on human life and socio-economic development in this region.

Corresponding author: Yanju Liu, National Climate Center (NCC), China Meteorological Administration (CMA), No. 46, Zhongguancun Nan Dajie Road, Haidian, Beijing 100081, China.

E-mail: liuyanj@cma.gov.cn

(C) 2011, Meteorological Society of Japan
Therefore, the research for the Meiyu and/or the TC activities over the western North Pacific (WNP) have been attached much importance, respectively (Ding 2004; Ding et al. 2007; Chan 2000; Wang and Chan 2002; Yumoto and Matsuura 2001). Because they both are greatly affected by the East Asian summer monsoon in warm season, one problem naturally arises as to their relationship. However, the relationship between Meiyu rainfall and TC activity has not been well understood. This is a complicated problem, since the TC can affect Meiyu directly or indirectly (Yamada and Kawamura 2007) and vice versa. From the 
view of energy and water budget, some correlation relationship between them should exist. For instance, once a TC forms, it will result in large-scale re-distribution of moisture and energy. Correspondingly, the moisture transport and budget over the other sensitive regions will be altered through large-scale circulations, thus influencing the occurrence of precipitation and its intensity over there. $\mathrm{He}$ and $\mathrm{Fu}$ (1992) previously noticed that there was a kind of negative correlation relationship between the Meiyu over the YHRB and the annual frequencies of TC genesis in the WNP. Lei and Chen (2001) also indicated that the genesis of active tropical cyclone usually takes up the moisture from the Bay of Bengal, thus intercepting or decreasing the moisture transport to the YHRB, and making the Meiyu to weaken, break or end. In contrast, there are few tropical cyclones during the active Meiyu period. Some numerical case studies have also revealed that the horizontal air-stream field triggered by the disturbance of TC could result in weakening of the low-level southwesterly wind flowing to East Asia (Xu et al. 1994). Consequently, the moisture transported to the YHRB by monsoonal airflow also became weaker. Chen and Cao (2006) have recently indicated that there was nearly no tropical cyclone over the region to the east of $140^{\circ} \mathrm{E}$ in the years with strong Meiyu precipitation.

Based on the above-mentioned studies, a negative correlation seems to exist between the rainfall of Meiyu and the frequencies of TC in the WNP, mostly due to their competition for the moisture supply over the East Asia-the WNP regions. However, such a relationship has just been examined only based on some case studies or shorterterm datasets. Therefore, a robust correlative relationship has not been obtained so far. More importantly, the mechanism of the negative correlation needs to be illuminated if there is any. Therefore, it is necessary to extend such a study with long-term series of data from viewpoint of climatology to reexamine this relationship. Also, it is crucial to improve understanding of the mechanism behind this correlative relationship and eventually, seek for possible precursors for anomalous summer precipitation over the eastern China.

The structure of the paper is as follows: Section 2 describes the datasets used in this study. The methodology of defining the Meiyu period is also presented. Section 3 examines the relationship between the Meiyu over the YHRB and the TC frequencies in the WNP. A comparative analysis of the years with more and fewer TCs is also presented in this section. The composite flow and moisture transport patterns associated with the positive and negative anomalies of TC genesis are analyzed in Section 4, respectively. Finally, conclusions and summary are given in Section 5.

\section{Data and methodology}

The data used in this study consist of the monthly reanalysis (1958-2000) from European Center for Medium-range Weather Forecast (ECMWF), the tropical cyclone data (1951-2006) from Joint Typhoon Warning Center (JTWC) and the precipitation observation data (1951-2006) at 743 observation stations of China from National Climate Center, China Meteorological Administration. In this study, the WNP is defined as the oceanic region of $0-50^{\circ} \mathrm{N}, 100-180^{\circ} \mathrm{E}$, including the South China Sea (SCS). The TC refers to those tropical cyclones with their sustained maximum wind speed exceeding $35 \mathrm{kt}$ or $18 \mathrm{~m} \cdot \mathrm{s}^{-1}$ (including tropical storms and typhoons). The formation location of each TC is determined objectively once the intensity reaches the tropical depression stage $(25 \mathrm{kt}$, or about $13 \mathrm{~m} \cdot \mathrm{s}^{-1}$ ). If a tropical disturbance intensifies to $35 \mathrm{kt}$, then the location at that time is used for TC genesis location. Thus, total 347 named TCs in the WNP for the Meiyu period from 1951 to 2006 are derived and the annual average number of TC in 56 years is about 6 . Figure 1 shows the distribution of the locations of TC genesis during the Meiyu

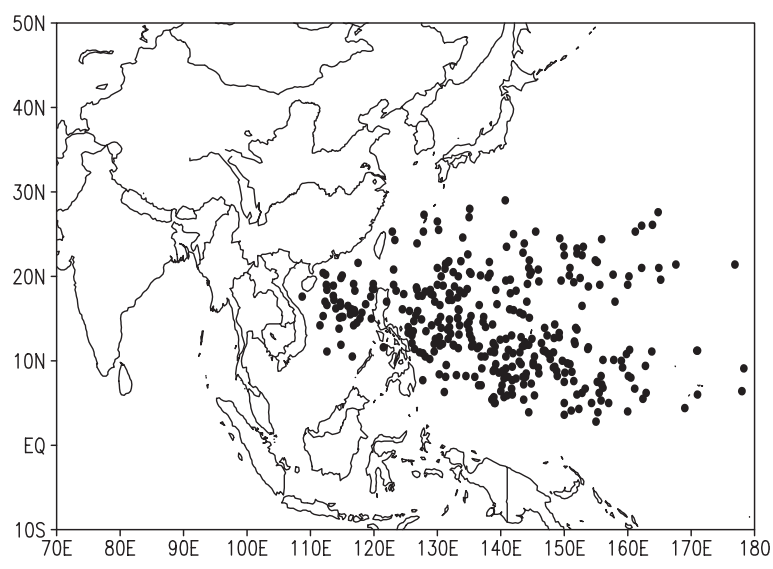

Fig. 1. Distribution of the locations of TC genesis during the Meiyu period (from June to July) from 1951-2006. See the text for the definition of TC genesis. 
period (from June to July) from 1951-2006. It can be seen that the most TCs mainly formed in the region of $5-20^{\circ} \mathrm{N}, 110-160^{\circ} \mathrm{E}$.

The Meiyu period is the main rainy season in the YHRB in summer, especially in its middle and lower reaches. Based on the previous study (Ding et al. 2007), the averaged onset and ending date of the Meiyu season is June 17 and July 8, respectively. However, these dates vary interannually. During those years with early onset, the rainy season over the YHRB usually starts at the end of May or early June, while for those years with late onset, the rainy season does not start until the end of June or early July. For some years with unusually early onset and unusually late ending (till the middle or the end of July) of Meiyu seasons, the rainy season may persist for about two months (e.g., 1954 and 1998). Therefore, the summer precipitation over the YHRB is mainly concentrated in June and July when the Meiyu precipitation occurs. In order to match with the large-scale monthly reanalysis data, the Meiyu period in this study is broadly defined as the two-month rainy period, namely from June to July. Although it is not strictly consistent with the exact duration of the individual Meiyu season, it covers almost all possible lifespans of Meiyu seasons.

\section{Relationship between the Meiyu over the YHRB and the frequencies of TC genesis in the WNP}

Figure 2 shows the correlation field between the precipitation at 743 stations in China and the frequencies of TC genesis during the Meiyu period (June and July) from 1951-2006. It shows that the most prominent negative correlation region is mainly located over the YHRB. The spatially averaged correlation coefficient over the lower reaches of the YHRB is greater than 0.4, exceeding 95\% confidence level (the degree of freedom is 54). Figure $3 \mathrm{a}$ shows the time series of the normalized frequencies of TC genesis and the precipitation during the Meiyu period from 1951 to 2006. The statistics indicates that the precipitation over the YHRB is negatively correlated with the frequencies of TC genesis. The temporally averaged correlation coefficient reaches -0.41 , which is significant at the $95 \%$ confidence level. From Figs. 3b, c, it can be seen that the interannual variations of the frequencies of TC genesis and the Meiyu precipitation are very prominent with about-two-year oscillations (TBO), namely positively anomalous years and negatively

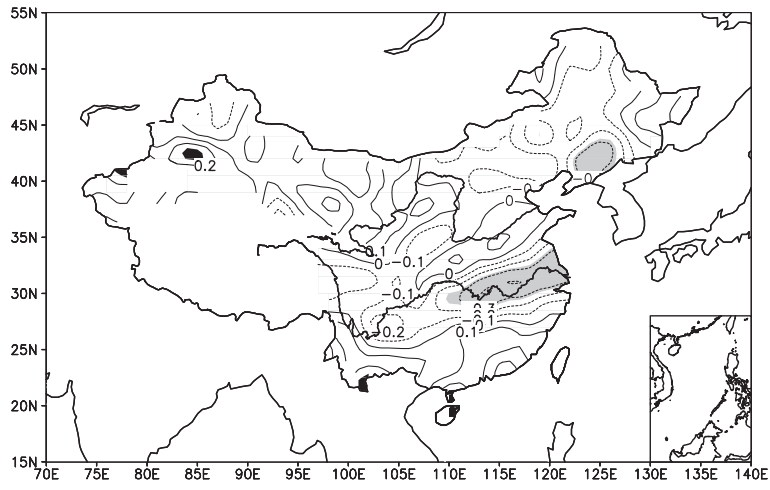

Fig. 2. The correlation field between the precipitation at 743 stations in China and the frequencies of TC genesis during the Meiyu period (from June to July) from 1951-2006. Solid (dashed) lines denote isolines of positive (negative) correlation. The shaded areas are statistically significant at $95 \%$ confidence level (dark shading for anomalous positive correlation and light shading for anomalous negative correlation).

anomalous years occur alternately. Also, both of them almost have the consistent 15-20-yr interdecadal oscillations, which implies that there likely exists a kind of negative correlation relationship between them at the longer time scale. In order to make a composite analysis of the anomalous correlative relationship, the standard deviation (SD) of +1 and -1 is defined as the threshold for choosing anomalous years. When the SD of normalized TC frequencies is lager than +1 , it is taken as the year of more TCs; oppositely, it is the year with less TCs. Thus seven years with more TCs $(1964,1965$, 1971, 1972, 1989, 1994, 2000) and ten years with fewer TCs (1951, 1953, 1954, 1956, 1957, 1959, $1969,1975,1983,1998)$ have been derived, respectively. It is estimated that the average number of TCs genesis for the Meiyu period in the years with more TCs is about 10, while in the years with fewer TCs there are only 2 TCs genesis. In order to be consistent with the large-scale reanalysis data, the lengths of the TC and precipitation data are also chosen as the period of 1958-2000.

\section{Composite analysis for anomalies of TC genesis frequencies}

The genesis and development of TC are closely associated with the large-scale circulations (Gray 

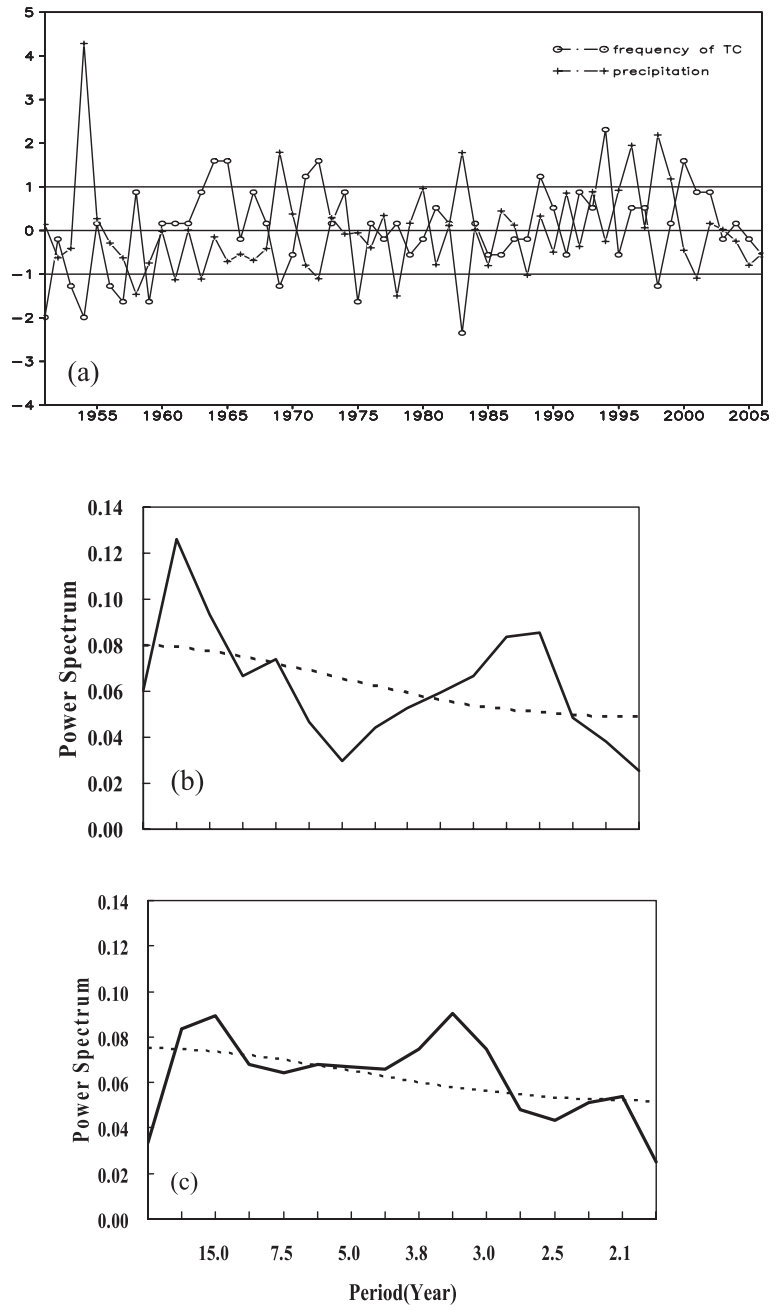

Fig. 3. (a) Time series of the normalized frequencies of TC genesis over the WNP and precipitation over the YHRB $\left(100-120^{\circ} \mathrm{E}\right.$, $\left.27.5-32.5^{\circ} \mathrm{N}\right)$ during the Meiyu period (from June to July) from 1951 to 2006. The line with circle refers to the frequencies of TC generation. The line with plus refers to the precipitation over the YHRB. (b) Power spectral density of normalized TC frequencies (solid line) with 95\% significance based on the red noise spectrum estimated from a first-order auto-regression. (c) Same as Fig. 3 (b), but for the normalized Meiyu precipitation over the YHRB.

1968, 1998; Ding and Reiter 1981; Cheung 2004). In order to understand the difference between the years with more and fewer TCs with respect to atmospheric conditions and moisture transport that are concurrently related to the TC genesis and
Meiyu precipitation, the fields of precipitation, $850 \mathrm{hPa}$ wind filed, $500 \mathrm{hPa}$ geopotential height, vertical wind shear as well as the moisture transport and regional budgets are investigated during the Meiyu period.

\section{1 $850 \mathrm{hPa}$ wind field}

Figure 4 shows the composite anomalous precipitation fields for the years with more and fewer TC genesis and their differences, respectively. Figure 5 is same as Fig. 4, but for the $850 \mathrm{hPa}$ wind fields. It is very clear that the precipitation and wind fields for the years with more TCs and the years with fewer TCs are remarkably different. In the years with fewer TCs (Fig. 5a), the monsoon trough is evidently weaker, which is only confined within the Indian Peninsula. A strong and anomalous closed anticyclonic circulation is found over the SCS and the WNP with its two centers located in $20^{\circ} \mathrm{N}$, $130^{\circ} \mathrm{E}$ and $25^{\circ} \mathrm{N}, 165^{\circ} \mathrm{E}$, respectively, which indicates the tropical monsoonal circulation is obviously weaker. To the north of this anomalous anticyclone (the East Asian continent and to the east of it) is an anomalous cyclonic circulation. Under this condition, the descending divergence circulation prevails over the SCS and the southern part of the WNP, which is unfavorable for the genesis and development of the TC. Whereas the strong southwesterly flow at the western flank of the anticyclone over the WNP moves northward and converges with the cold air from the mid- and high latitudes over the YHRB, thus leading to the occurrence of much precipitation (Fig. 4a). In contrast, in the years with more TCs (Fig. 5b), the tropical monsoonal trough is abnormally strong and the trough line extends eastward down to the dateline. The anomalous cyclonic circulation predominates over the SCS and the southern part of the WNP, which provides favorable conditions for the genesis and development of TC. In this situation, the low-level airflows are diffluent around the YHRB, and correspondingly the precipitation is abnormally less (Fig. 4b). It is evident from their difference that when the anomalous anticyclone controls the SCS and the WNP, the TC genesis over the WNP is abnormally less, but the precipitation over the YHRB is more abundant (Fig. 4c). Based on the above analysis, on one hand the number of TC genesis is closely related to the intensity of the tropical largescale monsoonal circulation, and on the other hand the precipitation and regional circulation patterns over the YHRB are also influenced by the tropical 

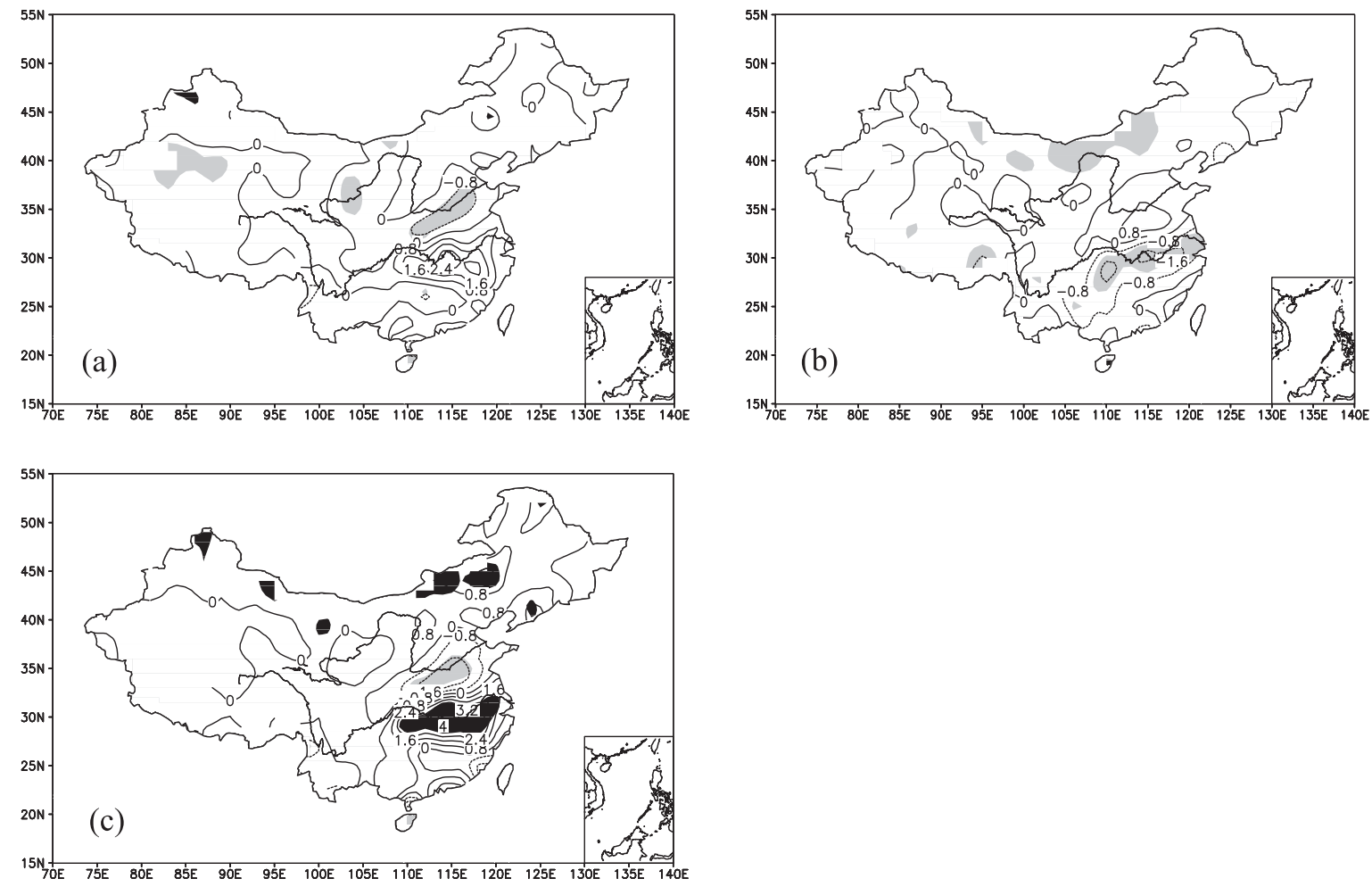

Fig. 4. Composite distributions of precipitation anomalies during the Meiyu period (from June to July) as well as their difference between the years with fewer and more TC genesis. The shaded areas are statistically significant at the confidence level of $95 \%$ (dark shading for anomalous positive precipitation anomalies and light shading for anomalous negative precipitation anomalies). (a) The years with fewer TC genesis, (b) the years with more TC genesis, and (c) their difference. The unit is $\mathrm{mm} \mathrm{day}^{-1}$.

large-scale monsoonal circulation (Ding et al. 1981; Ritchie and Holland 1999; Cheng et al. 1998).

\subsection{0 hPa geopotential field}

Figure 6 shows the $500 \mathrm{hPa}$ geopotential fields. From Fig. 6a, it can be seen that the two positive anomalous centers are located in the Ural mountain and the Sea of Okhotsk, respectively, while the negative anomaly center dominates most part of Asian continent, which demonstrates that in the years with fewer TCs two anomalous blocking highs usually exist over the mid- and high latitudes and a large low trough is located in between, e.g. the region of $60^{\circ}-140^{\circ} \mathrm{E}$. This kind of doubleblocking high situation has been regarded as one of the typical circulation systems during the Meiyu period, which is favorable for the cold air moving southward to the YHRB and above-normal Meiyu precipitation ( $\mathrm{Li}$ et al. 2008). Another positive anomaly is located in the south of $30^{\circ} \mathrm{N}$ over the WNP with its center at $20^{\circ} \mathrm{N}, 110^{\circ} \mathrm{E}$, which is unfavorable for the development of TCs. This configuration of $500 \mathrm{hPa}$ geopotential height in East Asia is very conducive to convergence of cold and warm airs over the YHRB. Whereas in the years with more TCs (Fig. 6b), the reverse anomalous height fields can be seen in the Eurasian continent, with the negative anomalies found over the Ural region and the Sea of Okhotsk, respectively, and the positive anomaly in between. In this situation, the subtropical high in the WNP is obviously farther to north, moving to the Yellow Sea and the Sea of Japan, which is favorable for tropical cyclone genesis (Ding 1994). Having examined their difference distribution (Fig. 6c), it is clearly shown that the subtropical high over the WNP is greatly significant at lower latitudes of around $20^{\circ} \mathrm{N}$, which is unfavorable for the formation of $\mathrm{TC}$. 

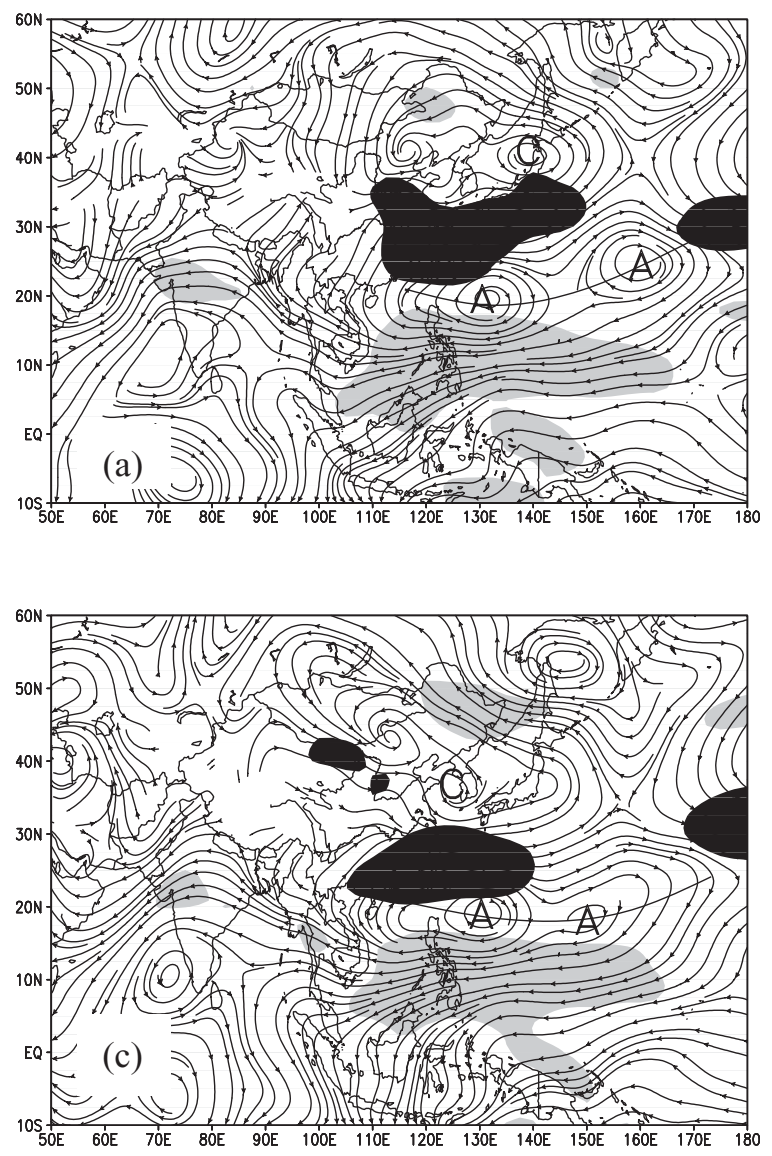

\section{3 $200 \mathrm{hPa}$ wind field}

Figure 7 presents the composite zonal wind patterns at $200 \mathrm{hPa}$. From Fig. 7a, it can be seen that the anomalously enhanced westerlies occur over the eastern costal areas of Asia and mid- and high latitudes of China, while easterly anomalies are found over the SCS and the southern part of the WNP. It can be seen that the position of the westerlies are located farther south and its intensity is stronger in the years with fewer TCs. This kind of wind configuration is favorable for the intrusion of the cold air from mid- and high latitudes and meeting with the warm air from the low latitudes in the YHRB, thus resulting in airflow convergence and increase of precipitation.

A stronger vertical wind shear is usually believed to be unfavorable for the occurrence and development of the TC (Gray 1998). Figure 8 presents the vertical shear field of the zonal winds between $200 \mathrm{hPa}$ and $850 \mathrm{hPa}$. The vertical wind shear is defined here as the difference of zonal winds at $200 \mathrm{hPa}$ and $850 \mathrm{hPa}$ (Clark and Chu 2002). From Fig. $8 \mathrm{a}$, it can be seen that the SCS and most of the

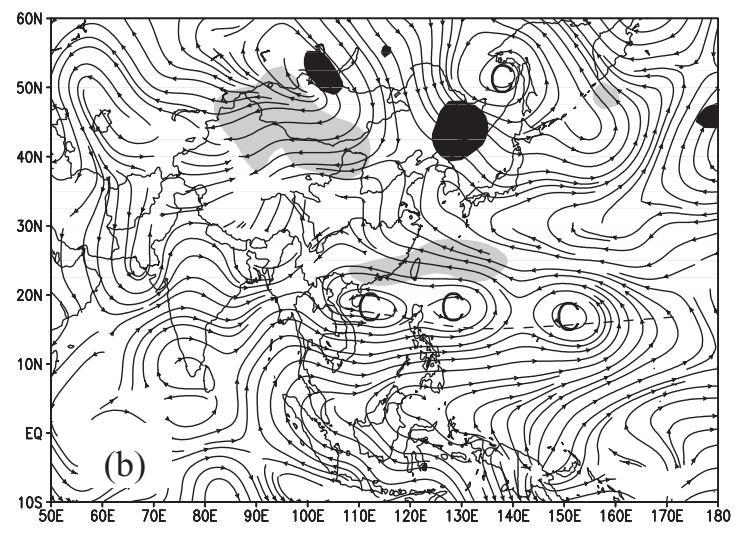

Fig. 5. Same as Fig. 4, but for the 850 streamline fields. The unit is $\mathrm{m} \mathrm{s}^{-1}$. The thick solid line denotes the ridge of anomalous anticyclone and the thick dashed line denotes the anomalous monsoon trough. The shaded areas are statistically significant at the 95\% confidence level (dark shading for anomalous positive $850 \mathrm{hPa}$ zonal wind and light shading for anomalous negative $850 \mathrm{hPa}$ zonal wind). (a) The years with fewer TC genesis, (b) the years with more TC genesis, and (c) their difference.

WNP are located in the positive vertical shear regions, which indicate the vertical shear over these regions are stronger, especially over the SCS. The weaker vertical shear mainly concentrates over the Maritime Continent region with the negative values. Whereas in the years with more TCs, there are noticeable enhanced easterlies over the eastern costal areas of Asia and mid- and low latitudes of China (Fig. 7b), which indicates that the tropical easterly jet over the WNP is stronger and the upper-level westerlies shift northward. Simultaneously, the whole WNP is nearly located over the region with relatively lower vertical wind shear values (Fig. 8b), which usually restrains the ventilation of troposphere and is favorable for the formation of the warm center of TC, namely genesis of the TC, due to decrease in ventilation in environment surrounding TC genesis regions. For their differences of $200 \mathrm{hPa}$ zonal wind and the vertical wind shear (Figs. 7c, 8c), they are similar to Figs. 7a, 8a, respectively, but the features of the mid-latitude westerlies and stronger wind shear values over the SCS and WNP are more apparently seen. 

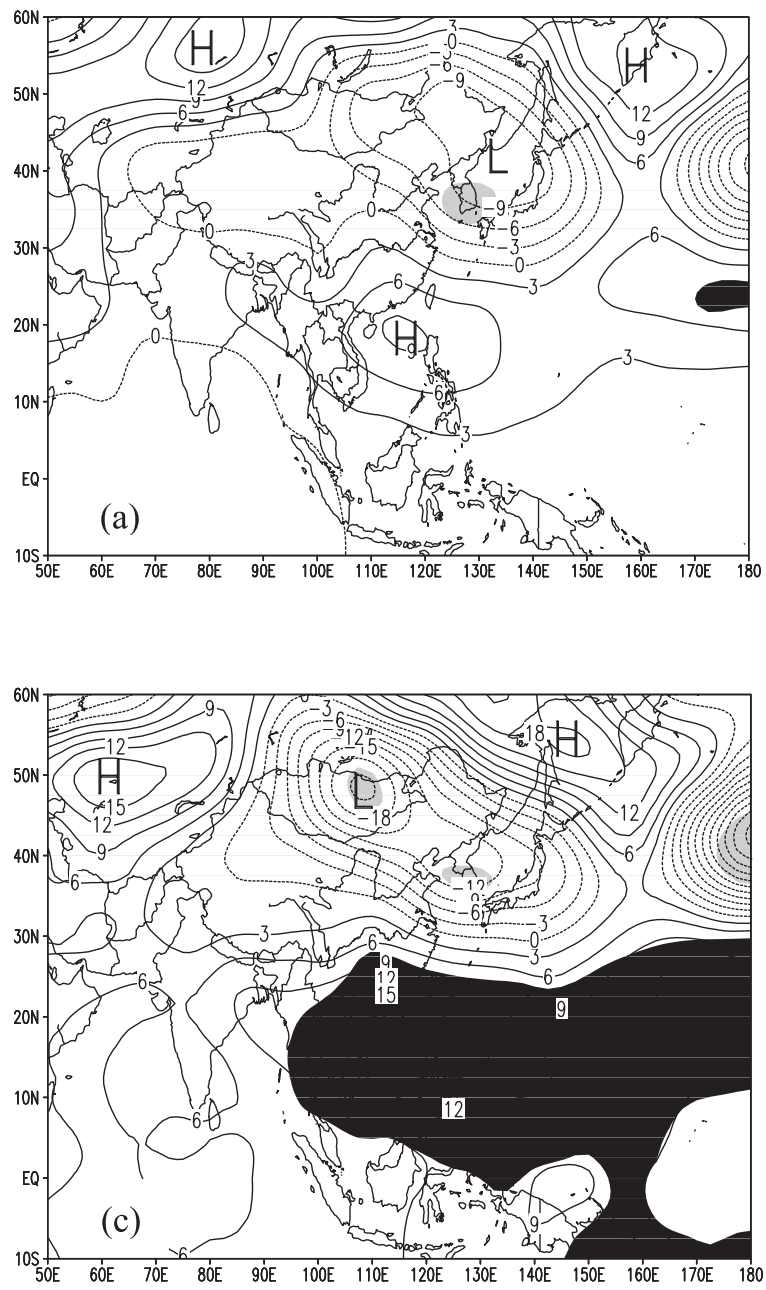

Based on the above-mentioned analysis, the negative correlation between the Meiyu over the YHRB and the frequencies of TC genesis in the WNP is established through the concerted variation of large-scale circulations in the tropical and midand high latitudes, which may suggest that the tropical-extratropical interaction plays an important role in this process, presumably through the effect of the TBO of tropical monsoon system (Chang et al. 2000; Tomita and Yasunari 1996).

\subsection{Moisture transport and moisture budget}

It is very important to further investigate the relationship between the Meiyu over the YHRB and the occurrence of TC in the WNP from the view of moisture flux transport and its budget. Figure 9 is the composite distributions of the moisture flux transport in the years with fewer and more TC genesis and their difference. It shows from Fig. 9a

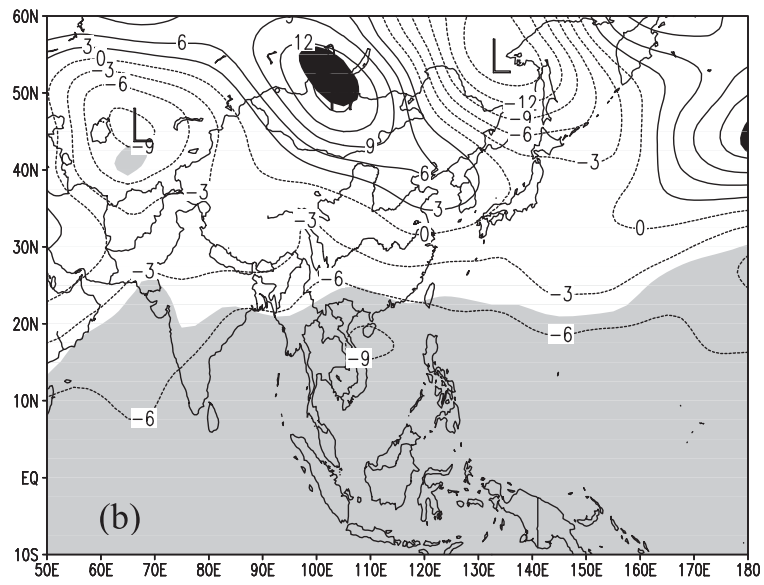

Fig. 6. Same as Fig. 4, but for the $500 \mathrm{hPa}$ geopotential height fields. The unit is gpm. The shaded areas are statistically significant at the 95\% confidence level (dark shading for anomalous positive $500 \mathrm{hPa}$ geopotential height and light shading for anomalous negative $500 \mathrm{hPa}$ geopotential height). (a) The years with fewer TC genesis, (b) the years with more TC genesis, and (c) their difference.

that a distinct anomalous anticyclonic moisture transport exists over the SCS and the southern WNP with its center at the Philippines. Influenced by it, the remarkably anomalous southeasterly moisture transport prevails over the region from the Philippines through the Bay of Bengal to the Indian Peninsula. Whereas the anomalous southwesterly moisture transport at the northwestern flank of this anticyclone converges with the anomalous northwesterly moisture transport coming from mid- and high latitudes over the middle and lower reaches of the YHRB, which corresponds to more precipitation over this region (Fig. 4a). In the years with more TCs, the anomalous easterly and southeasterly airflows forms the obvious moisture divergent field over the YHRB (Fig. 9b), which corresponds to remarkably less precipitation over the YHRB (Fig. 4b). One may see that a strong closed anomalous cyclonic moisture transport exists over 

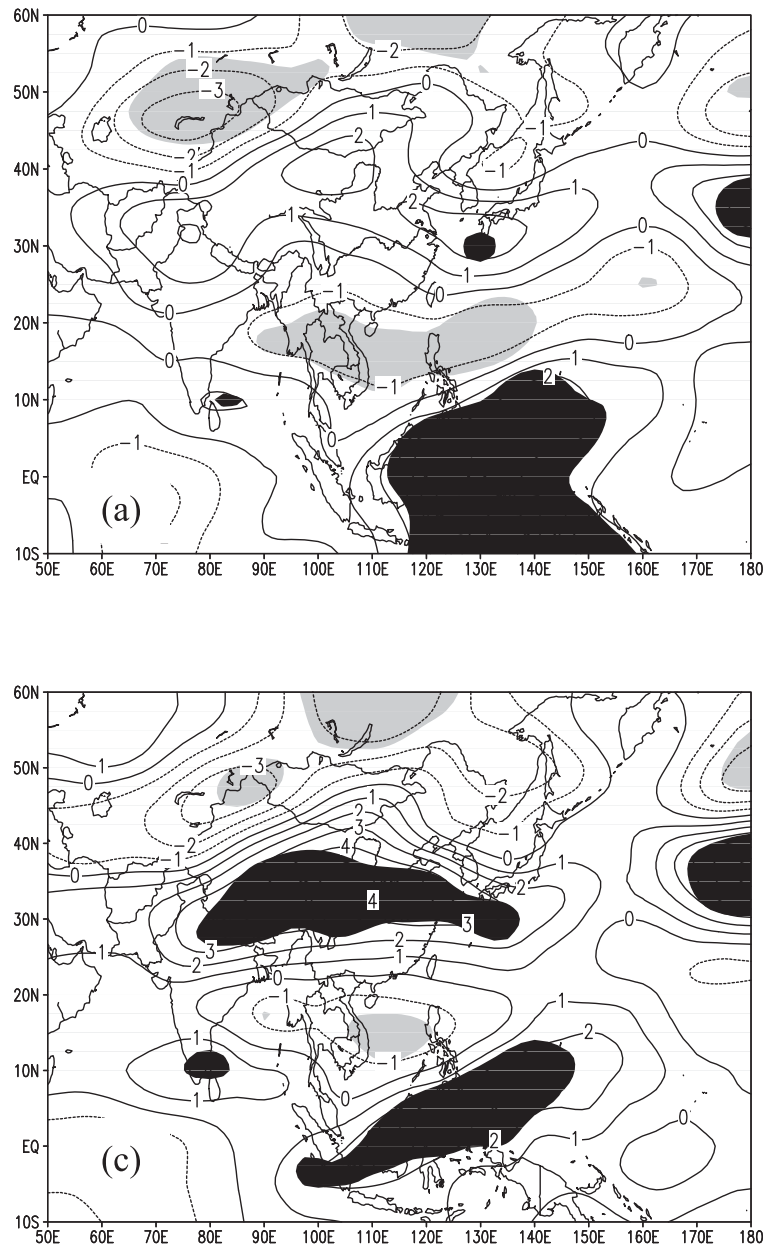

the southern WNP. Comparing the directions of the moisture transport between the anomalous positive and negative years of TC genesis, it can be noticed that they are greatly different. Due to tropical cyclones consisting of the anomalous horizontal convergence field in the lower troposphere taking up much moisture in the years with more TCs genesis, the remaining moisture flux transported into the YHRB is very weak, thus leading to weakening of convergence over this region. $\mathrm{Xu}$ et al. (1994) also pointed out the above-described result by a numerical study. From Fig. 9c, it can be further seen that there exists a marked anomalous anticyclonic moisture transport with its center at $20^{\circ} \mathrm{N}, 130^{\circ} \mathrm{E}$ when the precipitation over the YHRB is more.

The regional moisture budget mainly reflects the moisture source and sink, which is determined by the sum of the moisture flux across each boundary. Therefore, the moisture budgets of the YHRB and

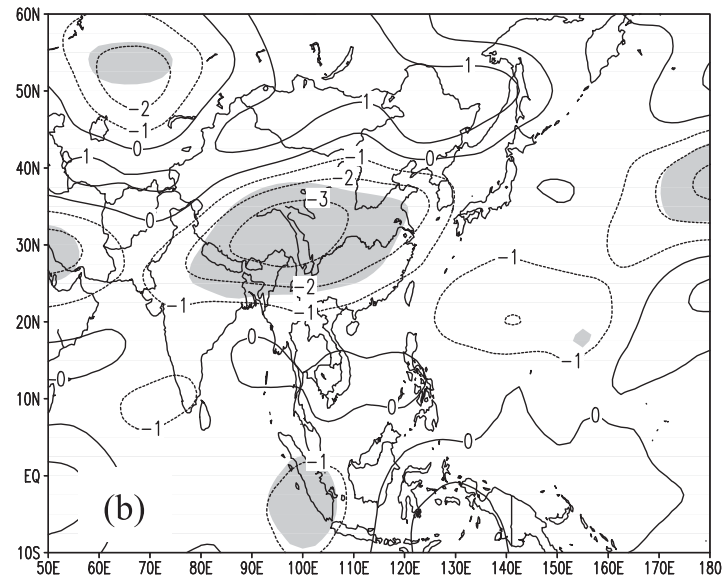

Fig. 7. Same as Fig. 4, but for the zonal winds at $200 \mathrm{hPa}$. The unit is $\mathrm{m} \mathrm{s}^{-1}$. The shaded areas are statistically significant at the $95 \%$ confidence level (dark shading for anomalous positive $200 \mathrm{hPa}$ zonal wind and light shading for anomalous negative $200 \mathrm{hPa}$ zonal wind). (a) The years with fewer TC genesis, (b) the years with more $\mathrm{TC}$ genesis, and (c) their difference.

the WNP region are quantitatively estimated. In order to carry out a systematic analysis from a more extensive region, the YHRB and the WNP regions as well as their adjacent regions are incorporated and further divided into 7 sub-regions: North China $\left(32.5^{\circ} \mathrm{N}-42^{\circ} \mathrm{N}, 100^{\circ} \mathrm{E}-120^{\circ} \mathrm{E}\right)$, the YHRB $\left(27.5^{\circ} \mathrm{N}-32.5^{\circ} \mathrm{N}, 100^{\circ} \mathrm{E}-120^{\circ} \mathrm{E}\right)$, South China $\left(22.5^{\circ} \mathrm{N}-27.5^{\circ} \mathrm{N}, 100^{\circ} \mathrm{E}-120^{\circ} \mathrm{E}\right)$, the Bay of Bengal $\left(0^{\circ}-22.5^{\circ} \mathrm{N}, 80^{\circ} \mathrm{E}-100^{\circ} \mathrm{E}\right)$, the SCS $\left(0^{\circ}-\right.$ $\left.22.5^{\circ} \mathrm{N}, 100^{\circ} \mathrm{E}-120^{\circ} \mathrm{E}\right)$, the southern part of the WNP $\left(0^{\circ}-22.5^{\circ} \mathrm{N}, 120^{\circ} \mathrm{E}-160^{\circ} \mathrm{E}\right)$, and the northern part of the WNP $\left(22.5^{\circ} \mathrm{N}-42^{\circ} \mathrm{N}, 120^{\circ} \mathrm{E}-160^{\circ} \mathrm{E}\right)$. Here, the positive and negative values represent net moisture influx and efflux, respectively. Figure 10 shows the schematic diagrams of anomalous moisture budgets for these sub-regions during Meiyu period in the years with anomalous TC genesis, respectively. From Fig. 10a, it can be easily found that in the years with fewer TCs genesis the moisture divergence occurs over the southern part 

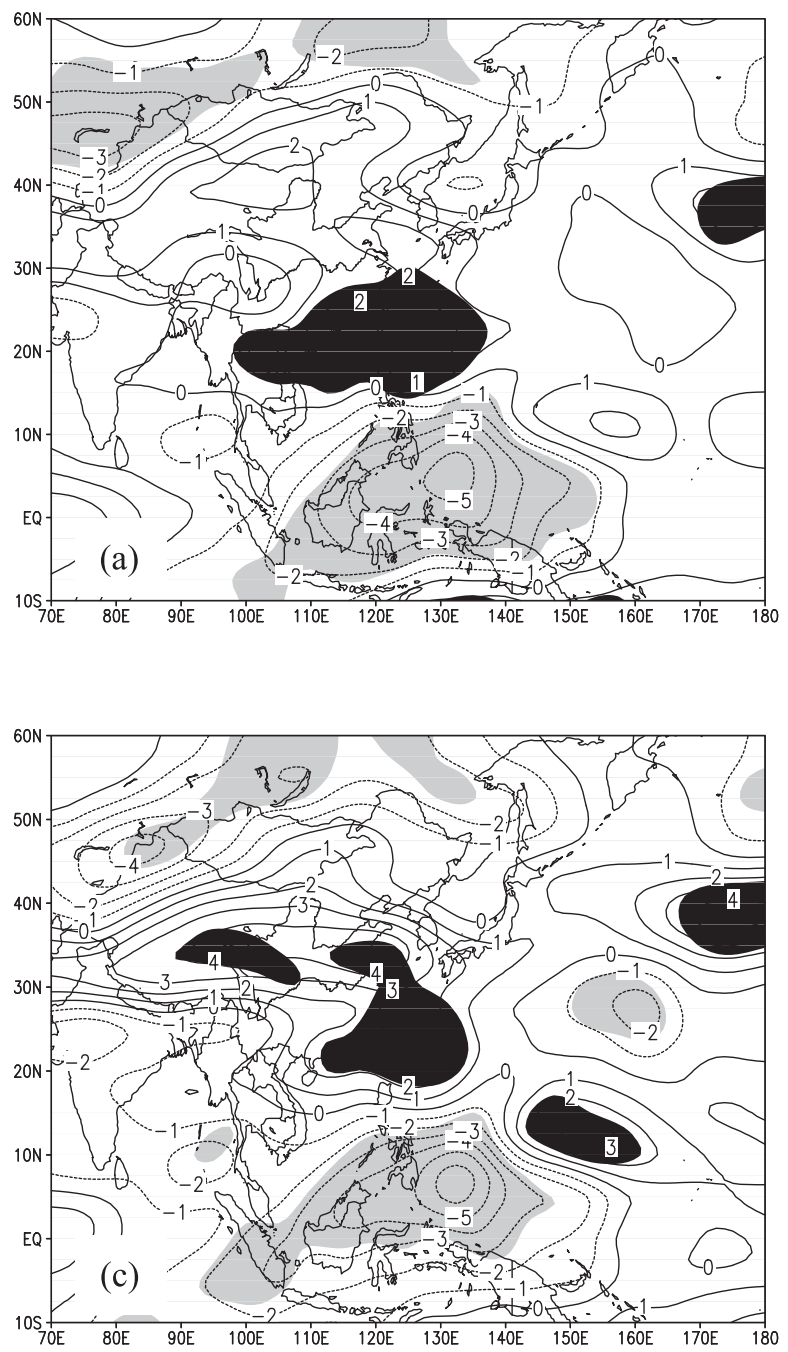

of the WNP, while for the YHRB it is a moisture convergent area, with moisture being imported into this region mainly by the anomalously strong southerly airflow. This branch of moisture transport can be traced back to the southern part of the WNP and then it goes to the middle and lower reaches of the Yangtze River through the SCS and South China. In the years with more TCs (Fig. $10 \mathrm{~b}$ ), the signs of the moisture budget in the WNP and YHRB are reverse. The anomalous tropical monsoonal moisture from the North Indian Ocean through the Bay of Bengal and the SCS all the way goes to the southern part of the WNP, thus providing a large amount of moisture more TC genesis requires. In this case, it can be seen that the moisture amount transported to the Meiyu area by southerlies remarkably decreases.

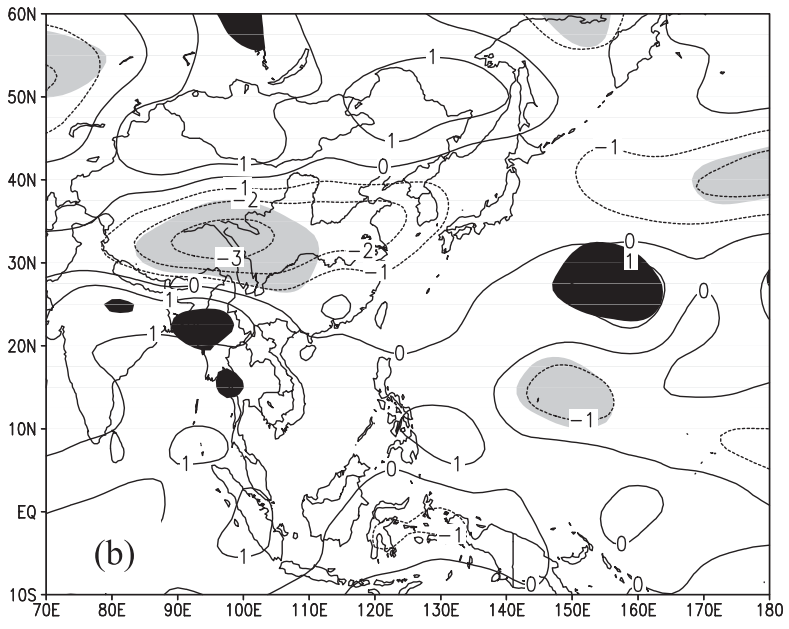

Fig. 8. Same as Fig. 4, but for the vertical shear fields of zonal winds between $200 \mathrm{hPa}$ and $850 \mathrm{hPa}$. The unit is $\mathrm{m} \cdot \mathrm{s}^{-1}$. The shaded areas are statistically significant at the $95 \%$ confidence level (dark shading for anomalous positive wind shear and light shading for anomalous negative wind shear). (a) The years with fewer TC genesis, (b) the years with more TC genesis, and (c) their difference.

\section{Conclusions}

The relationship between the Meiyu precipitation over the YHRB and the frequencies of TC genesis in the WNP as well as its mechanism has been investigated in this paper. The results have shown that there exists a significant negative correlation between them, which results from the fundamental change of monsoonal airflow and moisture transport over East Asia and the WNP. The following conclusions are drawn up:

(1) In the years with fewer TCs, the location of the main body of the subtropical high over the WNP is farther west and south, and its intensity is stronger. The monsoon trough is also located farther west with its intensity being weaker. Under this situation, the monsoon flow and the corre- 

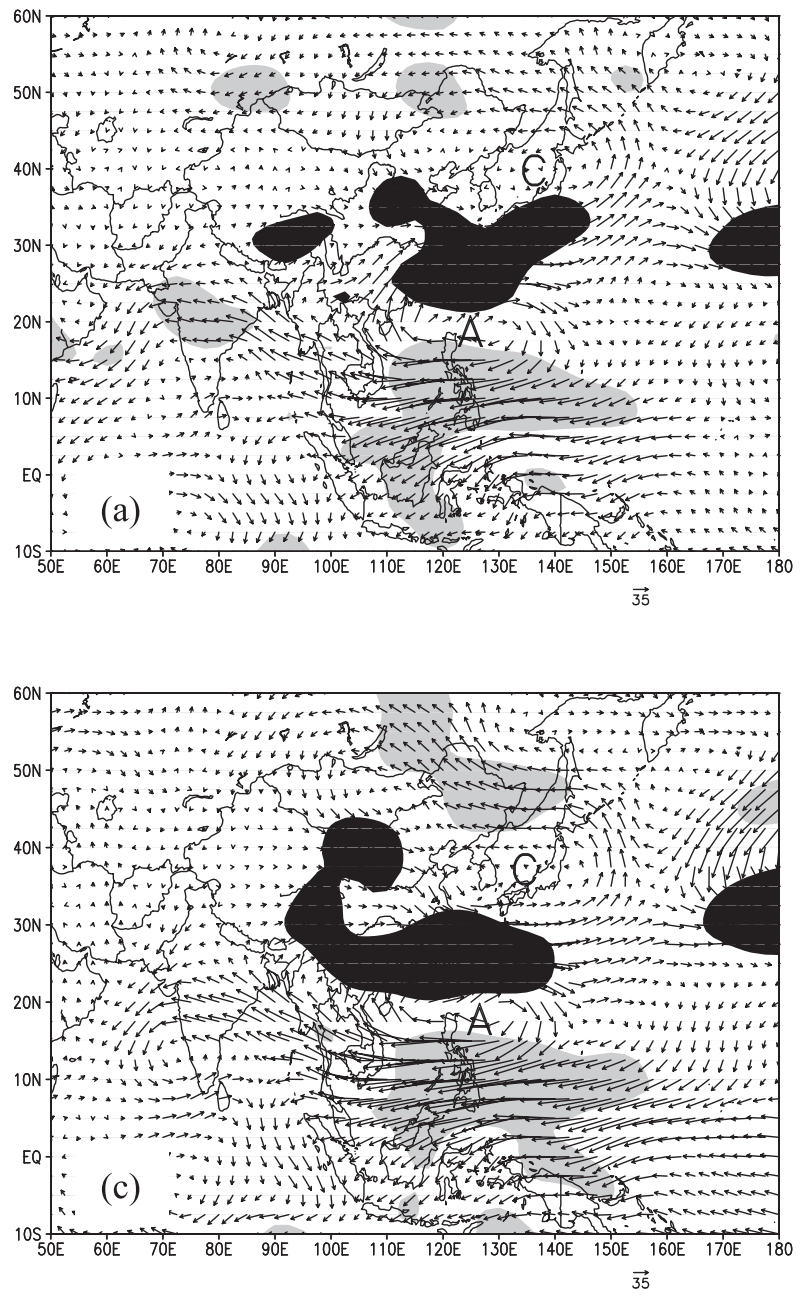

sponding moisture transport can not extend eastward to the WNP, but in the midway turns to East Asian region along the western rim of the subtropical anticyclone. Simultaneously, the location of the mid-latitude westerlies is farther south with stronger intensity. This kind of circulation configuration is favorable for the convergence of the dry and cold air from mid- and high latitudes and the warm and moist air from low latitudes over the YHRB, thus leading to precipitation increase, but it is unfavorable for the genesis and development of TC due to intercepting eastward moisture transport in the SCS. In the years with more TCs, the subtropical high over the WNP is located farther north and east with its intensity being weaker. The monsoon trough zonally extends eastward and its intensity is stronger. The monsoon flow and the moisture transport can all the way go to the WNP, with much less turning northward over the SCS and

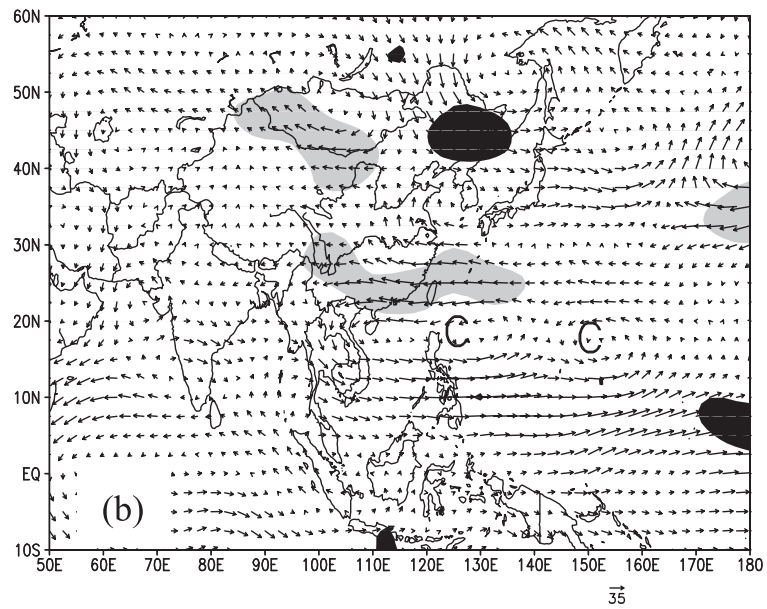

Fig. 9. Same as Fig. 4, but for the vertically integrated moisture transports. The unit is $\mathrm{kg} \cdot \mathrm{m}^{-1} \cdot \mathrm{s}^{-1}$. The shaded areas are statistically significant at the $95 \%$ confidence level (dark shading for anomalous positive zonal moisture transport and light shading for anomalous negative zonal moisture transport). (a) The years with fewer TC, (b) the years with more $\mathrm{TC}$, and (c) their difference

then moving to the East Asian Meiyu region. At the same time, the location of the westerlies is farther north and its intensity is weaker, which is also unfavorable for the occurrence of precipitation over the YHRB.

(2) In the years with fewer TCs, an area of obvious moisture flux divergence is found over the southern part of the WNP, whereas the strong moisture convergence area is found over the YHRB. The stronger southerly moisture transport originating in the WNP through the SCS and South China to the YHRB is the major moisture source which results in more precipitation over the YHRB. Whereas in the years with more TCs, the active TC genesis occurs in the WNP, usually owing to anomalous westerly monsoon moisture transport from the Bay of Bengal to the WNP, without turning northward in the SCS, thus making the precipitation decrease in the YHRB. 

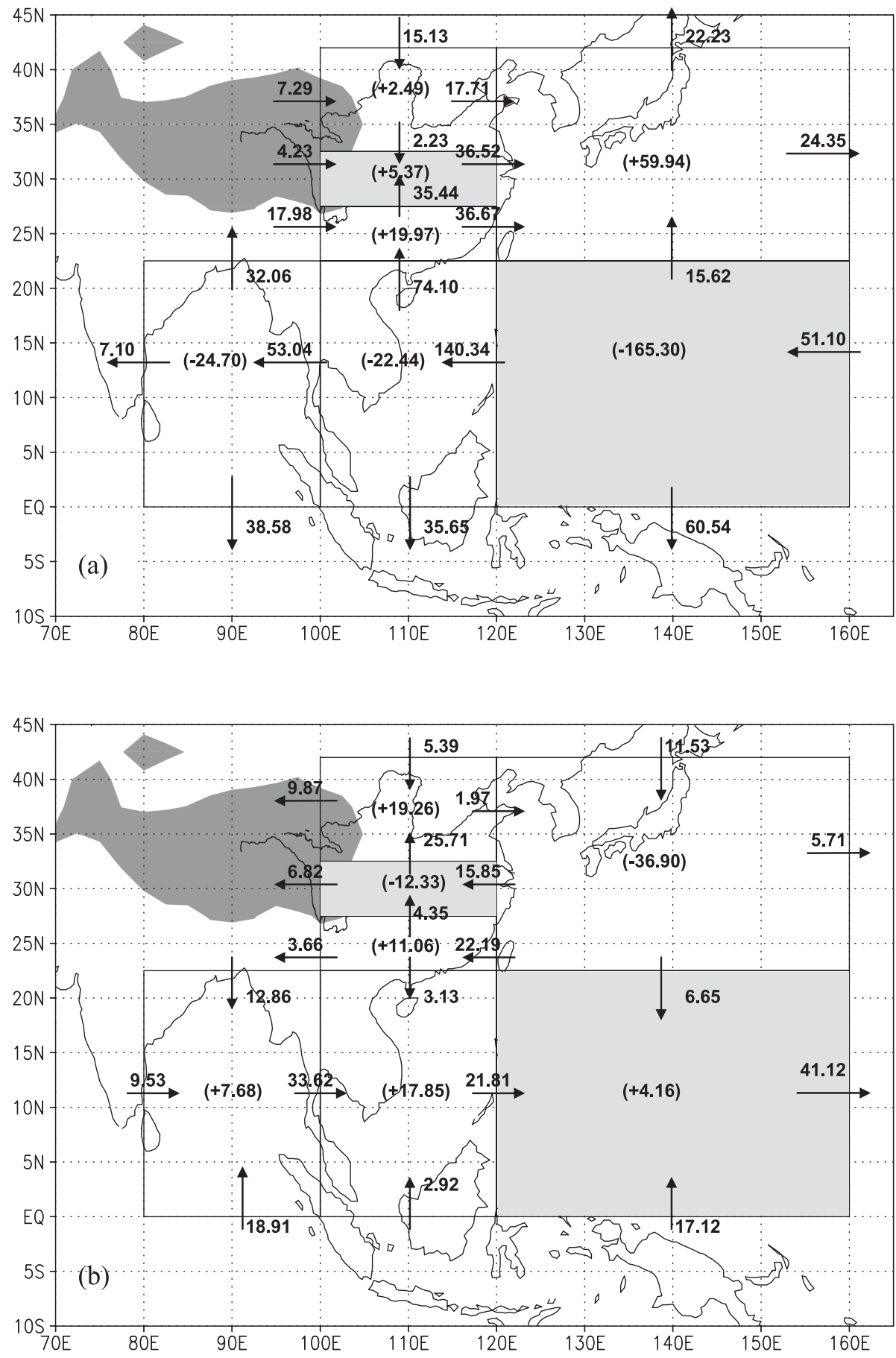

Fig. 10. Composite schematic diagrams of the anomalous moisture budget during the Meiyu period in the years with fewer (a) and more (b) TC genesis. The unit is $10^{6} \mathrm{~kg} \mathrm{~s}^{-1}$. The dark area denotes the Tibetan Plateau and the grey areas mean the YHRB and the southern part of the WNP, respectively. The arrow denotes the direction of moisture transport. The "+" and "-" means the net influx and efflux, respectively. 
The negative correlation relationship between precipitation over the YHRB and frequencies of TC genesis has been studied in this work mainly at inter-annual scale. However, it can be seen from the Figs. 3b, c that both of them almost have the consistent interdecadal oscillation, namely 15-20-yr oscillation, which implies that there likely exists some kind of correlation relationship between them for the interdecadal scale. It sounds an interesting subject, which is really worthy of being investigated in the future work.

The above-mentioned negative relationship will be useful for the seasonal climate forecast of the Meiyu and typhoon during flooding season in China or even in East Asia, which can be regarded as one kind of constraint conditions for Meiyu forecast, hereby judging the rationality of typhoon and Meiyu forecasts.

\section{Acknowledgements}

Permission to use the ECMWF reanalysis data, the TC data from Joint Typhoon Warning Center and the precipitation observation data at 743 stations of China from their respective institutions is gratefully acknowledged. This work is jointly sponsored by "973" Program No. 2006CB403604 and National Technology Support Program (2007BAC03A01). The insightful comments and helpful suggestions from two anonymous reviewers are highly appreciated.

\section{References}

Chan, J. C. L., 2000: Tropical cyclone activity over the western North Pacific associated with El Niño and La Niña events. J. Climate, 13, 2960-2972.

Chang, C.-P., Y. S. Zhang, and T. Li, 2000: Interannual and interdecadal variations of the East Asian summer monsoon and tropical Pacific SSTs. Part I: roles of the subtropical ridges. J. Climate, 13, 4310-4325.

Chen, Y. L., and X. G. Cao, 2006: Analysis of influence on strong Meiyu in Shanghai of tropical cyclone and relevant synoptic systems. J. Trop. Meteor., 22, 326-330 (in Chinese).

Cheng, T. C., S. P. Weng, N. Yamazaki, et al., 1998: Interannual variation in the tropical cyclone formation over the western tropical Pacific. Mon. Wea. Rev., 126, 1080-1090.

Cheung, K. K. W., 2004: Large-scale environmental parameters associated with tropical cyclone formations in the western North Pacific. J. Climate, 17, 466-484.
Clark, J. D., and P. S. Chu, 2002: Interannual variation of tropical cyclone activity over the central North Pacific. J. Meteor. Soc. Japan, 80, 403-418.

Ding, Y. H., and E. R. Reiter, 1981: Some conditions influencing the variability of typhoon formation over the West Pacific Ocean. Arch. Met. Geoph. Biokl. Ser. A, 30, 327-342.

Ding, Y. H., 1994: Monsoons over China. Kluwer Academic Publishers, Dordrecht/Boston/London, 419pp.

Ding, Y. H., 2004: Seasonal march of the East Asian summer monsoon. Chang C.-P. (ed.), East Asian Monsoon, World Scientific, 3-53.

Ding, Y. H., J. J. Liu, Y. Sun, et al., 2007: A study of the synoptic climatology of the Meiyu system in East Asia. Chinese J. Atmos. Sci., 31, 1082-1101 (in Chinese).

Gray, W. M., 1968: Global view of the origin of tropical disturbances and storms. Mon. Wea. Rev., 96, 669-700.

Gray, W. M., 1998: The formation of tropical cyclones. Meteor. Atmos. Phys., 67, 37-69.

He, S. X., and X. Q. Fu, 1992: On interannual variation of Meiyu and typhoon and their relationship. Meteorology, 18, 8-12 (in Chinese).

Lei, X. T., and L. S. Chen, 2001: Tropical cyclone land falling and its interaction with mid-latitude circulation systems. Acta Meteor. Sinica, 59, 602-615 (in Chinese).

Li, F., Y. H. Ding, and Y. Y. Bao, 2008: A study of the forming characteristics of blocking high in northern Asia during the flood period of the Huaihe River Basin in 2003. Chinese J. Atmos. Sci., 32, 469-480 (in Chinese).

Ritchie, E. A., and G. J. Holland, 1999: Large-scale patterns associated with tropical cyclogenesis in the western Pacific. Mon. Wea. Rev., 127, 2027-2043.

Tomita, T., and T. Yasunari, 1996: Role of the northeast winter monsoon on the biennial oscillation of the ENSO/Monsoon system. J. Meteor. Soc. Japan, 74, 399-413.

Wang, B., and J. C. L. Chan, 2002: How strong ENSO events affect tropical storm activity over the western North Pacific. J. Climate, 15, 1643-1658.

Xu, H. M., Q. Q. Wang, and Z. X. Ge, 1994: A numerical study of heat effect of typhoon 9106 on Meiyu ending. J. Trop. Meteor., 10, 231-237 (in Chinese).

Yamada, K., and R. Kawamura, 2007: Dynamical link between typhoon activity and the PJ teleconnection pattern from early summer to autumn as revealed by the JRA-25 reanalysis. SOLA, 3, 65-68.

Yumoto, M., and T. Matsuura, 2001: Interdecadal variability of tropical cyclone activity in the western North Pacific. J. Meteor. Soc. Japan, 79, 23-35. 